Original Article

\title{
Attitudes toward Risk-Reducing Mastectomy and Risk-Reducing Salpingo-oophorectomy among Young, Unmarried, Healthy Women in Korea
}

\author{
Boyoung Park ${ }^{11}$, Dongwon Kim², Jiyoung Kim², Bom Yi Lee², Junghyun Yoon ${ }^{3}$, Sung-Won Kim (1)2 \\ ${ }^{1}$ Department of Preventive Medicine, Hanyang University College of Medicine, Seoul, ${ }^{2}$ Department of Surgery, Daerim St. Mary's Hospital, Seoul, \\ ${ }^{3}$ Department of Health Sciences, Hanyang University College of Medicine, Seoul, Korea
}

Purpose This study investigated the attitudes toward risk-reducing mastectomy (RRM) and risk-reducing salpingo-oophorectomy (RRSO) as cancer prevention options for BRCA1/2 carriers in healthy, young, unmarried Korean women.

Materials and Methods A nationally representative sample of 600 women, aged 20-39 years, completed a questionnaire on sociodemographic variables, preference for genetic testing, and intention to undergo risk-reducing surgeries after receiving information on the cancer risk of $B R C A 1 / 2$ mutations and benefits of risk-reducing surgeries.

Results A total of $54.7 \%$ and $57.7 \%$ had the intention to undergo RRM and RRSO, respectively, on the assumption that they were BRCA1/2 carriers. Older age and no intention to undergo genetic testing were associated with a reduced likelihood of undergoing RRM (odds ratio [OR], 0.30; 95\% confidence interval [Cl], 0.14 to 0.61 for age 35-39 years and OR, 0.35; $95 \% \mathrm{Cl}, 0.20$ to 0.62 for no intention for genetic testing) and RRSO (OR, 0.39; $95 \% \mathrm{Cl}, 0.19$ to 0.79 for age 35-39 years and OR, 0.30; $95 \% \mathrm{Cl}, 0.17$ to 0.53 for no intention for genetic testing). Women who chose to be single were likely to undergo risk-reducing surgeries $(\mathrm{OR}, 1.67 ; 95 \% \mathrm{Cl}, 1.07$ to 2.60 for RRM and OR, 1.56; 95\% Cl, 1.00 to 2.44 for RRSO).

Conclusion More than $50 \%$ of healthy, unmarried, young Korean women were inclined to undergo prophylactic surgeries if they were BRCA1/2 mutation carriers. Further studies on decision-making process for cancer prevention in individuals at high risk for cancer need to be conducted.

Key words BRCA mutation, Risk-reducing mastectomy, Risk-reducing salpingo-oophorectomy

\section{Introduction}

Mutations in BRCA1 or BRCA2 genes are responsible for a substantially increased lifetime risk of breast cancer $(57 \%$ and $49 \%$, respectively) and ovarian cancer (40\% and $18 \%$, respectively) [1]. In the South Korean population, the breast cancer risk until the age of 70 years was estimated to be $49 \%$ and $35 \%$ in BRCA1 and BRCA2 mutation carriers [2]. In case of non-carriers, the lifetime risk of breast and ovarian cancers is $12.9 \%$ [3] and $1.4 \%$ [4] in Caucasians and $5.8 \%$ and $0.7 \%$ in South Koreans [5].

Ever since the news of Angelina Jolie's decision to undergo risk-reducing mastectomy (RRM) and risk-reducing bilateral salpingo-oophorectomy (RRSO) in 2013 and 2015, given her $B R C A 1$ carrier status and family history, made headlines, the public's awareness of double mastectomy and hereditary cancer has increased but with a lack of accurate interpretations [6]. In addition, the breast cancer prevention services such as breast cancer screening, genetic screening, and riskreducing prophylactic surgeries has increased in Western countries, a phenomenon known as the "Angelina Jolie effect" [7]. In South Korea, since medical coverage for $B R C A 1 / 2$ screening test by the National Health Insurance system started in 2012 and with the rise of the Angelina Jolie effect, the popularity of BRCA1/2 gene testing and prophylactic management has increased. The number of contralateral mastectomy and salpingo-oophorectomy for prophylactic purposes among breast cancer patients with BRCA1/2 mutations has also increased [8,9].

Given the increased awareness, insurance coverage for genetic testing, and advancements in genetic testing technologies [8,10], the perceptions of and attitudes to risk-reducing surgeries need to be assessed not only for BRCA1/2 carriers or breast cancer patients with a family history of cancer but also for generally healthy women. In this study, the attitudes toward RRM and RRSO as cancer prevention options for $B R C A 1 / 2$ carriers and factors associated with the preference for risk-reducing surgeries among healthy, young, unmarried South Korean women were assessed.

Correspondence: Sung-Won Kim

Department of Surgery, Daerim St. Mary's Hospital, 657 Siheung-daero, Yeongdeungpo-gu, Seoul 07442, Korea

Tel: 82-2-829-9515 Fax: 82-2-833-6224 E-mail: brcakorea@gmail.com

Received April 10, 2021 Accepted August 6, 2021 Published Online August 9, 2021 


\section{Materials and Methods}

\section{Participants}

A cross-sectional telephone survey was conducted in the year of 2020 with 600 cancer-free unmarried women aged 2039 years. The participants from the 17 regional strata were stratified according to the administrative districts in South Korea. The study population in each stratum was proportionally designated as the total population aged 20-39 in the strata identified by the 2019 resident registration in South Korea. Equal proportions of women aged 20-29 and 30-39 years were recruited. Cell phone numbers were randomly generated for computer-assisted telephone interviews. Three calls were made in cases of no response before moving to the next number. After obtaining consent to participate in the survey, the women were asked about their birth year, residential area, marital status, and past history of cancer; women who were aged $\leq 20$ or $\geq 40$ years, married, or had a history of cancer diagnosis were excluded.

Besides the sociodemographic variables of education, job, and income, intentions toward marriage and childbearing and family history of breast or ovarian cancer were also recorded. Participants were provided information on lifetime breast and ovarian cancer risks in BRCA1/2 mutation carriers (maximum $80 \%$ and 50\%, respectively). Next, the preference for genetic test services for BRCA1/2 was obtained. Furthermore, information on the reduced risk of breast and ovarian cancers after RRM with reconstruction surgery (up to 90\% reduction in the risk of breast cancer) and RRSO (85\% reduction in the risk of ovarian cancer and $70 \%$ reduction in ovarian cancer-related death), with respect to Angelina Jolie's decision, was provided. It took approximately 5 minutes to explain cancer risk related to $B R C A$ mutation and prophylactic surgeries.

\section{Data analysis}

The study participants' characteristics, including sociodemographic factors; family history of breast or ovarian cancer; and attitudes toward marriage, childbearing, and genetic testing are summarized as numbers and frequencies. Preference for RRM and RRSO according to the characteristics of the participants is presented as a percentage. The association between each participant's character and preference for RRM and RRSO was determined using simple logistic regression analysis. Then, the independent association of each factor with the preference for RRM and RRSO was assessed using multiple logistic regression analysis including all variables. The results are presented as odds ratio (OR) and 95\% confidence interval (CI). All statistical analyses were performed using SAS ver. 9.4 (SAS Institute, Cary, NC).
Table 1. Baseline characteristics of the participants

\begin{tabular}{|c|c|}
\hline Characteristic & No. $(\%)(\mathrm{n}=600)$ \\
\hline \multicolumn{2}{|l|}{ Age (yr) } \\
\hline 20-24 & $102(17.0)$ \\
\hline $25-29$ & $192(32.0)$ \\
\hline $30-34$ & $201(33.5)$ \\
\hline $35-39$ & $105(17.5)$ \\
\hline \multicolumn{2}{|l|}{ Education } \\
\hline High school or below & $62(10.3)$ \\
\hline Undergraduate & $92(15.3)$ \\
\hline College or above & $446(74.3)$ \\
\hline \multicolumn{2}{|l|}{ Income $(\$ / y r)$} \\
\hline None & $63(10.5)$ \\
\hline$<30,000$ & $227(37.8)$ \\
\hline $30,000-49,999$ & $211(35.2)$ \\
\hline$\geq 50,000$ & $99(16.5)$ \\
\hline \multicolumn{2}{|l|}{ Occupation } \\
\hline Blue collar & $71(11.8)$ \\
\hline White collar & $363(60.5)$ \\
\hline Student & $72(12.0)$ \\
\hline Others & $15(2.5)$ \\
\hline None & $79(13.2)$ \\
\hline \multicolumn{2}{|l|}{ Residential area } \\
\hline Metropolitan city & $446(74.3)$ \\
\hline Others & $154(25.7)$ \\
\hline \multicolumn{2}{|c|}{ Family history of breast or ovarian cancer } \\
\hline Neither & $492(82.0)$ \\
\hline Only breast cancer & $91(15.2)$ \\
\hline Only ovarian cancer & $8(1.3)$ \\
\hline Both & $9(1.5)$ \\
\hline \multicolumn{2}{|c|}{ Attitude toward marriage and childbearing } \\
\hline Want children & $318(53.0)$ \\
\hline Do not want children & $139(23.2)$ \\
\hline Want to remain single & $143(23.8)$ \\
\hline \multicolumn{2}{|c|}{ Attitude toward genetic test } \\
\hline Agree & $534(89.0)$ \\
\hline Disagree & $66(11.0)$ \\
\hline
\end{tabular}

\section{Results}

Table 1 shows the baseline characteristics of the study participants. Among 600 women aged 20-39 years, 18\% had a family history of either breast or ovarian cancer; $53 \%$ intended to marry and bear children, $23.2 \%$ intended to marry but did not want to bear children, and $23.8 \%$ wanted neither marriage nor childbearing; $89.0 \%$ wanted to undergo genetic testing for $B R C A 1 / 2$.

Further, $54.7 \%$ and $57.7 \%$ had the intention to undergo RRM and RRSO, respectively, on the assumption that they were $B R C A 1 / 2$ carriers. As age increased, the proportion of women with the intention to undergo RRM or RRSO 
Table 2. Proportion of women who are willing to undergo riskreducing mastectomy

\begin{tabular}{|c|c|c|}
\hline Variable & $\begin{array}{l}\text { Risk-reducing } \\
\text { mastectomy }(\%)\end{array}$ & $\begin{array}{c}\text { Risk-reducing } \\
\text { bilateral } \\
\text { salpingo- } \\
\text { oophorectomy (\%) }\end{array}$ \\
\hline Total & 54.7 & 57.7 \\
\hline \multicolumn{3}{|l|}{$\operatorname{Age}^{a)}(y r)$} \\
\hline $20-24$ & 65.7 & 66.7 \\
\hline $25-29$ & 64.1 & 65.6 \\
\hline $30-34$ & 47.3 & 51.7 \\
\hline $35-39$ & 41.0 & 45.7 \\
\hline \multicolumn{3}{|l|}{ Education } \\
\hline High school or below & 56.5 & 61.3 \\
\hline Undergraduate & 54.4 & 58.7 \\
\hline College or above & 54.5 & 57.0 \\
\hline \multicolumn{3}{|l|}{ Income $(\$ / y r)$} \\
\hline$<30,000$ & 55.9 & 57.6 \\
\hline$\geq 30,000$ & 53.6 & 57.7 \\
\hline \multicolumn{3}{|l|}{ Occupation } \\
\hline Blue collar & 49.3 & 62.0 \\
\hline White collar & 53.7 & 55.3 \\
\hline Student & 65.9 & 59.7 \\
\hline Others & 66.7 & 73.3 \\
\hline None & 59.5 & 59.5 \\
\hline \multicolumn{3}{|l|}{ Residential area } \\
\hline Metropolitan city & 54.3 & 57.0 \\
\hline Others & 55.8 & 59.7 \\
\hline \multicolumn{3}{|l|}{$\begin{array}{l}\text { Attitude to marriage } \\
\text { and having children }\end{array}$} \\
\hline Want children & 53.1 & 56.6 \\
\hline Do not want children & 49.6 & 54.0 \\
\hline Want to remain single & 62.9 & 63.6 \\
\hline \multicolumn{3}{|l|}{$\begin{array}{l}\text { Family history of breast } \\
\text { or ovarian cancer }\end{array}$} \\
\hline Neither & 55.3 & 58.5 \\
\hline $\begin{array}{l}\text { Either breast or } \\
\text { ovarian cancer }\end{array}$ & 51.9 & 53.7 \\
\hline \multicolumn{3}{|c|}{ Attitude to genetic testing ${ }^{\text {a) }}$} \\
\hline Agree & 57.5 & 60.9 \\
\hline Disagree & 31.8 & 31.8 \\
\hline
\end{tabular}

${ }^{\mathrm{a})} \mathrm{p}<0.05$, for both risk-reducing mastectomy and risk-reducing salpingo-oophorectomy. Other factors did not show significant differences.

decreased from $>65 \%$ in the 20-24-age group to around $40 \%$ in the 35-39-age group (Table 2). Those who wanted to undergo screening for $B R C A 1 / 2$ mutations had a significantly high intention to undergo risk-reducing surgeries $(\mathrm{p}<0.05)$.

Factors associated with the intention to undergo RRM are presented in Table 3. As age increased, the intention to undergo RRM was less in the 30-34-age group (OR, 0.39; 95\% CI, 0.20 to 0.74 ) and in the 35-39-age group (OR, 0.30; 95\% CI, 0.14 to 0.61$)$ than in the 20-24 age group. Women who did not want to undergo genetic testing were less likely to undergo RRM (OR, $0.35 ; 95 \%$ CI, 0.20 to 0.62$)$ than those who wanted to. Women who chose to be single were more likely to undergo RRM than those who did not (OR, $1.67 ; 95 \% \mathrm{CI}$, 1.07 to 2.60$)$.

Factors associated with the intention to undergo RRSO are presented in Table 4, showing comparable results with RRM. Older age and no intention to undergo genetic testing were associated with less preference for RRSO (OR for 30-34 years, 0.49 ; $95 \%$ CI, 0.25 to 0.94 ; OR for $35-39$ years, 0.39 ; $95 \% \mathrm{CI}$, 0.19 to 0.79 compared with 20-24 age group; OR for rejection of genetic testing, $0.30 ; 95 \% \mathrm{CI}, 0.17$ to 0.53 ). Women who chose to be single were more likely to undergo RRSO than those who did not (OR, 1.56; 95\% CI, 1.00 to 2.44).

\section{Discussion}

This study assessed the attitudes toward risk-reducing surgeries, namely RRM and RRSO, in a representative sample of unmarried women aged 20-39 years who did not undergo BRCA1/2 screening or counseling in South Korea, on the assumption that they were carriers of the BRCA1/2 mutation. Most previous studies on the uptake of prevention options, including risk-reducing surgeries, focused on BRCA1/2 mutation carriers or high-risk women; limited information exists on generally healthy women who have never received genetic counseling or screening.

In all, $54.7 \%$ and $57.7 \%$ of the young women had a positive attitude toward RRM and RRSO, respectively. Our percentages are higher than that reported a study in Italy where only $24.3 \%$ of the young women chose RRSO in a hypothetical scenario of BRCA1/2 carrier status [11] and higher than those reported in a study targeting high-risk women who underwent genetic counseling $23.3 \%$ and $42.5 \%$ considered RRM and RRSO, respectively) [12]. A study conducted in South Korea also reported that only $27 \%$ of the patients from outpatient plastic surgery clinics agreed to undergo RRM if necessary [13]. However, a recent study on women who received genetic counseling showed that $49.2 \%$ and $61.3 \%$ of women had intentions to undergo RRM and RRSO, respectively [14], comparable with our results, with strong intentions in unaffected BRCA1/2 mutation carriers (63\% and $89 \%$ for RRM and RRSO, respectively) [15]. Increased awareness after the Angelina Jolie effect and genetic counseling may have caused the increased interest in risk-reducing surgeries, especially RRM [7] and the increased preference for riskreducing surgeries would reflect this. In South Korea, since 
Table 3. Attitudes toward risk-reducing mastectomy among those who assumed they were a BRCA carrier

\begin{tabular}{|c|c|c|}
\hline \multirow{2}{*}{ Variable } & \multicolumn{2}{|c|}{ OR $(95 \% \mathrm{CI})$} \\
\hline & Crude OR & Adjusted OR \\
\hline \multicolumn{3}{|l|}{ Age (yr) } \\
\hline $20-24$ & 1 & 1 \\
\hline $25-29$ & $0.93(0.56-1.54)$ & $0.75(0.39-1.43)$ \\
\hline $30-34$ & $0.47(0.29-0.77)$ & $0.39(0.20-0.74)$ \\
\hline $35-39$ & $0.36(0.21-0.64)$ & $0.30(0.14-0.61)$ \\
\hline \multicolumn{3}{|l|}{ Education } \\
\hline High school or below & 1 & 1 \\
\hline Undergraduate & $0.92(0.48-1.76)$ & $0.81(0.37-1.76)$ \\
\hline College or above & $0.92(0.54-1.58)$ & $0.99(0.55-1.80)$ \\
\hline \multicolumn{3}{|l|}{ Income (\$/yr) } \\
\hline$<30,000$ & 1 & 1 \\
\hline$\geq 30,000$ & $0.91(0.66-1.26)$ & $0.94(0.66-1.34)$ \\
\hline \multicolumn{3}{|l|}{ Occupation } \\
\hline Blue collar & 1 & 1 \\
\hline White collar & $1.19(0.72-1.99)$ & $1.18(0.68-2.06)$ \\
\hline Student & $1.36(0.70-2.63)$ & $0.82(0.35-1.93)$ \\
\hline Others & $2.06(0.64-6.63)$ & $1.67(0.49-5.72)$ \\
\hline None & $1.51(0.79-2.88)$ & $1.25(0.63-2.50)$ \\
\hline \multicolumn{3}{|l|}{ Residential area } \\
\hline Metropolitan city & 1 & 1 \\
\hline Others & $1.07(0.74-1.54)$ & $1.04(0.70-1.54)$ \\
\hline \multicolumn{3}{|c|}{ Attitude to marriage and having children } \\
\hline Want children & 1 & 1 \\
\hline Do not want children & $0.87(0.58-1.30)$ & $0.91(0.60-1.39)$ \\
\hline Want to remain single & $1.50(1.00-2.24)$ & $1.67(1.07-2.60)$ \\
\hline \multicolumn{3}{|c|}{ Family history of breast or ovarian cancer } \\
\hline Neither & 1 & 1 \\
\hline Either breast or ovarian cancer & $0.87(0.57-1.32)$ & $0.79(0.51-1.23)$ \\
\hline \multicolumn{3}{|l|}{ Attitude to genetic testing } \\
\hline Agree & 1 & 1 \\
\hline Disagree & $0.35(0.20-0.60)$ & $0.35(0.20-0.62)$ \\
\hline
\end{tabular}

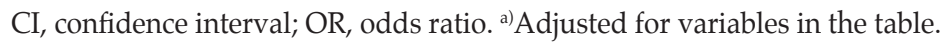

the public disclosure of Jolie's condition, the number of hospitals and clinicians providing BRCA1/2 screening and riskreducing surgeries has rapidly increased [9], resulting in increased preferences in the South Korean population. The aforementioned Italian study asked women to choose only one option among several risk-reducing options, including surveillance, surgery, or oral contraceptives [11]; thus, the overall preference for risk-reducing surgery would be higher.

Previous studies have shown that prevention decisions vary according to age. Older age was associated with a decreased intention to undergo RRM but increased intention to undergo RRSO among high-risk women $[12,16,17]$. Although a protective effect of RRSO is expected when performed early [18] in BRCA1/2 mutation carriers, the negative effects of RRSO, such as infertility, postmenopausal symptoms, and other health and mental problems, especially childbearing issues $[12,19]$ would explain the reduced preference for RRSO. The high risk of early onset breast cancer has been associated with a strong preference for RRM in the young age group as an immediate option for reducing risk [12]. In this study, as age increased, the preference for both RRM and RRSO decreased. In another study, the intention to undergo RRSO in South Korean BRCA1/2 mutation carriers increased as their age decreased owing to insufficient explanations provided on RRSO to older carriers [20], as seen in our study. In this study, the short explanation on riskreducing surgeries might emphasize the benefit and neglect the harm, especially childbearing issues of RRSO, present- 
Table 4. Attitudes toward risk-reducing bilateral salpingo-oophorectomy among those who assumed they were a $B R C A$ carrier

\begin{tabular}{|c|c|c|}
\hline \multirow{2}{*}{ Variable } & \multicolumn{2}{|c|}{ OR $(95 \% \mathrm{CI})$} \\
\hline & Crude OR & Adjusted OR ${ }^{a)}$ \\
\hline \multicolumn{3}{|l|}{ Age (yr) } \\
\hline $20-24$ & 1 & 1 \\
\hline $25-29$ & $0.96(0.57-1.59)$ & $0.86(0.45-1.65)$ \\
\hline $30-34$ & $0.54(0.33-0.88)$ & $0.49(0.25-0.94)$ \\
\hline $35-39$ & $0.42(0.24-0.74)$ & $0.39(0.19-0.79)$ \\
\hline \multicolumn{3}{|l|}{ Education } \\
\hline High school or below & 1 & 1 \\
\hline Undergraduate & $0.90(0.47-1.73)$ & $0.86(0.40-1.88)$ \\
\hline College or above & $0.84(0.49-1.44)$ & $0.93(0.51-1.70)$ \\
\hline \multicolumn{3}{|l|}{ Income (\$/yr) } \\
\hline$<30,000$ & 1 & 1 \\
\hline$\geq 30,000$ & $1.01(0.73-1.39)$ & $1.08(0.76-1.55)$ \\
\hline \multicolumn{3}{|l|}{ Occupation } \\
\hline Blue collar & 1 & 1 \\
\hline White collar & $0.76(0.45-1.28)$ & $0.69(0.39-1.22)$ \\
\hline Student & $0.91(0.47-1.78)$ & $0.56(0.23-1.33)$ \\
\hline Others & $1.69(0.49-5.83)$ & $1.31(0.36-4.75)$ \\
\hline None & $0.90(0.47-1.74)$ & $0.74(0.37-1.49)$ \\
\hline \multicolumn{3}{|l|}{ Residential area } \\
\hline Metropolitan city & 1 & 1 \\
\hline Others & $1.12(0.77-1.63)$ & $1.11(0.75-1.65)$ \\
\hline \multicolumn{3}{|c|}{ Attitude to marriage and having children } \\
\hline Want children & 1 & 1 \\
\hline Do not want children & $0.90(0.60-1.34)$ & $0.95(0.63-1.45)$ \\
\hline Want to remain single & $1.34(0.89-2.02)$ & $1.56(1.00-2.44)$ \\
\hline \multicolumn{3}{|c|}{ Family history of breast or ovarian cancer } \\
\hline Neither & 1 & 1 \\
\hline Either breast or ovarian cancer & $0.82(0.54-1.25)$ & $0.76(0.49-1.18)$ \\
\hline \multicolumn{3}{|l|}{ Attitude to genetic testing } \\
\hline Agree & 1 & 1 \\
\hline Disagree & $0.30(0.17-0.52)$ & $0.30(0.17-0.53)$ \\
\hline
\end{tabular}



ing higher preference in younger age groups. The lack of an association between age and intention to undergo RRSO in general young women [11] supports this finding.

$B R C A 1 / 2$ mutation carriers were likely to undergo prophylactic surgeries if they had children or had more children, suggesting that completion of childbearing is an important factor in the decision-making process $[17,21,22]$. Previous studies reported that women who wanted to have children in the future and those who wanted more children were less likely to consider prophylactic surgeries than those who did not want children [11]. In this study, attitudes toward marriage were associated with the intention to undergo riskreducing surgeries, with a positive attitude seen more in women who wanted to be single than in women who did not.
Among breast cancer patients without BRCA1/2 mutations, married patients chose to receive prophylactic contralateral mastectomy more frequently than unmarried patients [23]. Our study population was composed of unmarried women; thus, the future possibility of marriage was closely associated with the intention to undergo prophylactic surgeries. Thus, not only childbearing but also marriage intentions should be part of the genetic counseling for unmarried young women.

The association between the attitude to undergo genetic testing and intention to undergo prophylactic surgeries has rarely been investigated because most relevant studies targeted women who received genetic counseling. Those who did not want to undergo genetic testing were less likely to undergo risk-reducing surgeries if they were $B R C A 1 / 2$ 
mutation carriers than those who were open to genetic testing. This may be owing to an insufficient understanding or knowledge. The majority of the general population does not have sufficient knowledge to accurately interpret information on the cancer risk related to BRCA1/2 mutations [6] and previous knowledge and increased comprehension of genetic testing are associated with an increased odds of intention to undergo RRSO [11]. In addition, unaffected adults with family members who are BRCA1/2 mutation carriers had a low risk perception, followed by low acceptance of riskreducing surgeries [24]. Thus, detailed information needs to be provided to the population.

Studies on associations between family history of breast or ovarian cancer and intention to receive prophylactic surgeries in BRCA1/2 mutation carriers or high-risk women have shown inconsistent results $[14,25,26]$. Family history of cancer is highly associated with perceived risk [27,28], and perceived risk highly correlated with the increased interest in prophylactic surgeries among high-risk women in most studies $[16,25,28]$. Studies have shown a strong, complex relationship between family history and intention to undergo prophylactic surgeries, considering the objective impact of risk and subjective impact of the experience of relatives with cancer [25]. Another study on healthy young women did not find an association among the perceived likelihood of cancer risk, family history of breast or ovarian cancer, and intentions to undergo risk-reducing surgeries, similar to this study [11] rather, cancer worry was associated with the intention to undergo prophylactic surgeries. Thus, decision making with respect to cancer prevention could involve people's risk, experience of genetic counseling, comprehension of explanation, and previous knowledge.

Another interesting finding in this study was that in young, healthy, unmarried women, factors associated with RRM and RRSO were similar, with similar strengths of associations. Two reviews involving high-risk women proposed comparable factors and associations with the decision to undergo RRM and RRSO [25,26].

This study had several limitations. First, we used a hypothetical situation involving generally healthy women and not the attitudes of women who were actually at a high risk of breast cancer or were BRCA1/2 mutation carriers. Their responses could be different from those of individuals at risk such as women with a family history of breast cancer or mutation carriers of highly susceptible genes. Second, though the women's perceived risk or cancer-related worry largely impacted the intention to undergo prophylactic surgery $[16,25,28]$, we did not measure it. Instead, we assessed patients' family history of breast and ovarian cancers. In addition, as participants were selected from the general population of Korea, the individual risks of breast cancer estimated by breast cancer risk assessment tools and effectiveness of preventive interventions may have been different. Third, previous studies have shown a complex process of decision making, including demographic, socioeconomic, psychological, social, and emotional factors as well as objective information and input from others, for preventive options [25]. However, this study did not include all these factors. Fourth, the understanding regarding the risk of cancer in BRCA mutation carriers and the benefits and harms of RRM and RRSO could be limited because information was provided during a telephonic survey. If video materials or internet webpages explaining the cancer risk related to $B R C A$ mutation and prophylactic surgeries had been provided before the telephonic survey, the participants would have had more understanding. If video materials or internet webpages explaining the cancer risk related to $B R C A$ mutation and prophylactic surgeries had been provided before telephone survey, the participants would have had more understanding. Despite of these limitations, this study included a relatively large representative sample, reflecting the attitudes of women aged 20-39 years in South Korea. In addition, the findings of this study were comparable with those of studies on attitudes toward risk-reducing surgery among women before genetic testing and counseling or the general population [11,12], possibly extending our results to East Asian women with $B R C A 1 / 2$ mutations.

In this study, more than $50 \%$ of the young, unmarried, healthy Korean women had intentions to undergo RRM and RRSO if they were BRCA1/2 mutation carriers. Younger age, being unmarried, and desire for genetic testing were associated with a high likelihood of intention to undergo RRM and RRSO. Further studies regarding the intention of wellinformed individuals at a high risk for hereditary cancer such as people with a family history of cancer or hereditary gene carriers to undergo RRM and RRSO need to be conducted. In addition, studies are needed to elucidate the decisionmaking process for cancer prevention in high-risk groups of hereditary or sporadic cancers.

\section{Ethical Statement}

This study was approved by the Institutional Review Board of the Hanyang University College of Medicine (IRB no. HYI-20-175-1). Informed consent was obtained from all participants.

\section{Author Contributions}

Conceived and designed the analysis: Kim D, Kim SW.

Collected the data: Kim J, Lee BY, Kim SW.

Contributed data or analysis tools: Park B, Kim J, Lee BY.

Performed the analysis: Park B, Yoon J.

Wrote the paper: Park B, Kim D, Kim J, Lee BY, Yoon J, Kim SW. 


\section{ORCID iDs}

Boyoung Park ${ }^{(\mathbb{D})}$ : https: // orcid.org/0000-0003-1902-3184

Sung-Won Kim ${ }^{D}$ : https:// orcid.org/0000-0001-5687-1380

Conflicts of Interest

Conflict of interest relevant to this article was not reported.

\section{Acknowledgments}

This work was supported by the National Research Foundation of Korea (NRF) grant funded by the Korea government(MSIT) (grant number 2021R1A2C1011958).

\section{References}

1. Chen S, Parmigiani G. Meta-analysis of BRCA1 and BRCA2 penetrance. J Clin Oncol. 2007;25:1329-33.

2. Park B, Dowty JG, Ahn C, Win AK, Kim SW, Lee MH, et al. Breast cancer risk for Korean women with germline mutations in BRCA1 and BRCA2. Breast Cancer Res Treat. 2015;152:659. 65.

3. Mauer C, Spencer S, Dungan J, Hurley K. Exploration of male attitudes on partnerships and sexuality with female BRCA1/2 mutation carriers. J Genet Couns. 2016;25:290-7.

4. Pearce CL, Stram DO, Ness RB, Stram DA, Roman LD, Templeman $\mathrm{C}$, et al. Population distribution of lifetime risk of ovarian cancer in the United States. Cancer Epidemiol Biomarkers Prev. 2015;24:671-6.

5. Smith KR, Ellington L, Chan AY, Croyle RT, Botkin JR. Fertility intentions following testing for a BRCA1 gene mutation. Cancer Epidemiol Biomarkers Prev. 2004;13:733-40.

6. Borzekowski DL, Guan Y, Smith KC, Erby LH, Roter DL. The Angelina effect: immediate reach, grasp, and impact of going public. Genet Med. 2014;16:516-21.

7. Metcalfe K, Eisen A, Senter L, Armel S, Bordeleau L, Meschino WS, et al. International trends in the uptake of cancer risk reduction strategies in women with a BRCA1 or BRCA2 mutation. Br J Cancer. 2019;121:15-21.

8. Lee J, Kim S, Kang E, Park S, Kim Z, Lee MH, et al. Influence of the Angelina Jolie announcement and insurance reimbursement on practice patterns for hereditary breast cancer. J Breast Cancer. 2017;20:203-7.

9. Jung SM, Ryu JM, Park HS, Park JS, Kang E, Lee S, et al. Trends in risk-reducing mastectomy and risk-reducing salpingooophorectomy in Korean carriers of the BRCA1/2 mutation. J Breast Cancer. 2020;23:647-55.

10. Calabro GE, Sassano M, Tognetto A, Boccia S. Citizens' attitudes, knowledge, and educational needs in the field of omics sciences: a systematic literature review. Front Genet. 2020;11:570649.

11. Gavaruzzi T, Tasso A, Franiuk M, Varesco L, Lotto L. A psychological perspective on factors predicting prophylactic salpingo-oophorectomy in a sample of Italian women from the general population: results from a hypothetical study in the context of BRCA mutations. J Genet Couns. 2017;26:1144-52.

12. Tong A, Kelly S, Nusbaum R, Graves K, Peshkin BN, Valdimarsdottir $\mathrm{HB}$, et al. Intentions for risk-reducing surgery among high-risk women referred for BRCA1/BRCA2 genetic counseling. Psychooncology. 2015;24:33-9.
13. Yoon HY, Shim JS, Lee JW. Perceptions of prophylactic mastectomy in Korea. Arch Plast Surg. 2016;43:53-8.

14. Ladd MK, Peshkin BN, Senter L, Baldinger S, Isaacs C, Segal $\mathrm{H}$, et al. Predictors of risk-reducing surgery intentions following genetic counseling for hereditary breast and ovarian cancer. Transl Behav Med. 2020;10:337-46.

15. Mansfield CA, Metcalfe KA, Snyder C, Lindeman GJ, Posner J, Friedman $S$, et al. Preferences for breast cancer prevention among women with a BRCA1 or BRCA2 mutation. Hered Cancer Clin Pract. 2020;18:20.

16. Singh K, Lester J, Karlan B, Bresee C, Geva T, Gordon O. Impact of family history on choosing risk-reducing surgery among BRCA mutation carriers. Am J Obstet Gynecol. 2013;208:329.

17. Skytte AB, Gerdes AM, Andersen MK, Sunde L, BrondumNielsen K, Waldstrom $\mathrm{M}$, et al. Risk-reducing mastectomy and salpingo-oophorectomy in unaffected BRCA mutation carriers: uptake and timing. Clin Genet. 2010;77:342-9.

18. Grann VR, Jacobson JS, Thomason D, Hershman D, Heitjan DF, Neugut AI. Effect of prevention strategies on survival and quality-adjusted survival of women with BRCA1/2 mutations: an updated decision analysis. J Clin Oncol. 2002;20:2520-9.

19. Manchanda R, Burnell M, Abdelraheim A, Johnson M, Sharma A, Benjamin E, et al. Factors influencing uptake and timing of risk reducing salpingo-oophorectomy in women at risk of familial ovarian cancer: a competing risk time to event analysis. BJOG. 2012;119:527-36.

20. Kim D, Kang E, Hwang E, Sun Y, Hwang Y, Yom CK, et al. Factors affecting the decision to undergo risk-reducing salpingooophorectomy among women with BRCA gene mutation. Fam Cancer. 2013;12:621-8.

21. Friebel TM, Domchek SM, Neuhausen SL, Wagner T, Evans DG, Isaacs C, et al. Bilateral prophylactic oophorectomy and bilateral prophylactic mastectomy in a prospective cohort of unaffected BRCA1 and BRCA2 mutation carriers. Clin Breast Cancer. 2007;7:875-82.

22. Stuckey A, Dizon D, Scalia Wilbur J, Kent J, Tejada-Berges T, Gass J, et al. Clinical characteristics and choices regarding risk-reducing surgery in BRCA mutation carriers. Gynecol Obstet Invest. 2010;69:270-3.

23. Howard-McNatt M, Schroll RW, Hurt GJ, Levine EA. Contralateral prophylactic mastectomy in breast cancer patients who test negative for BRCA mutations. Am J Surg. 2011;202:298-302.

24. Foster C, Evans DG, Eeles R, Eccles D, Ashley S, Brooks L, et 
al. Predictive testing for BRCA1/2: attributes, risk perception and management in a multi-centre clinical cohort. Br J Cancer. 2002;86:1209-16.

25. Padamsee TJ, Wills CE, Yee LD, Paskett ED. Decision making for breast cancer prevention among women at elevated risk. Breast Cancer Res. 2017;19:34.

26. Park SY, Kim Y, Kim S. Factors associated with the decision to undergo risk-reducing salpingo-oophorectomy among women at high risk for hereditary breast and ovarian cancer: a sys- tematic review. Korean J Women Health Nurs. 2020;26:285-99.

27. Katapodi MC, Lee KA, Facione NC, Dodd MJ. Predictors of perceived breast cancer risk and the relation between perceived risk and breast cancer screening: a meta-analytic review. Prev Med. 2004;38:388-402.

28. Tilburt JC, James KM, Sinicrope PS, Eton DT, Costello BA, Carey J, et al. Factors influencing cancer risk perception in high risk populations: a systematic review. Hered Cancer Clin Pract. 2011;9:2. 